\title{
AS CHUVAS NA REGIÃO DE SÃO CARLOS/SP: ANÁLISE DOS VALORES MÁXIMOS DIÁRIOS NA SÉRIE HISTÓRICA, 1993-2014
}

\author{
Rafael Greco Sanches ${ }^{(a)}$, Bruno César dos Santos ${ }^{(b)}$, Mauricio Sanches Duarte Silva ${ }^{(\mathrm{c})}$, Francisco \\ Arthur Silva Vecchia ${ }^{(\mathrm{d})}$ \\ (a) Laboratório de Climatologia e Conforto Térmico, Centro de Recursos Hídrico e Educação Ambiental (CRHEA), \\ Escola de Engenharia de São Carlos (EESC), Universidade de São Paulo (USP). Email: rafagsanches@usp.br \\ (b) Laboratório de Climatologia e Conforto Térmico, Centro de Recursos Hídrico e Educação Ambiental (CRHEA), \\ Escola de Engenharia de São Carlos (EESC), Universidade de São Paulo (USP). Email: bruno-unifal@hotmail.com \\ (c) Laboratório de Climatologia e Conforto Térmico, Centro de Recursos Hídrico e Educação Ambiental (CRHEA), \\ Escola de Engenharia de São Carlos (EESC), Universidade de São Paulo (USP). Email: mauriciosanches@usp.br \\ (d) Programa de Pós-Graduação em Ciências da Engneharia Ambiental/Escola de Engenharia de São Carlos, \\ Universidade de São Paulo (USP), fvecchia@ sc.usp.br
}

\section{Eixo: CLIMATOLOGIA EM DIFERENTES NÍVEIS ESCALARES: MUDANÇAS E VARIABILIDADES}

\begin{abstract}
Resumo
O presente estudo objetivou analisar o comportamento pluviométrico em um único dia de chuvoso na região de São Carlos/SP a partir de três estações climatológicas na série histórica de 1993-2014 com a aplicação da ferramenta RClimdex e do índice climático RX 1, que expressa o valor máximo de chuva em um dia. Notou-se que o valor médio do RX 1 dia fora de 79,8 $\mathrm{mm}$ e, em todos os anos, houve ao menos um dia acima de $48 \mathrm{~mm}$ e, em média, $80 \%$ dos anos estiveram próximos ao valor médio. Além disso, a média do valor máximo acumulado em um único encontrou-se próxima a $80 \mathrm{~mm}$, bem como espera-se que ocorram dias chuvosos com, ao menos, $45 \mathrm{~mm}$ num único dia. Entretanto, notou-se que os valores sazonais apontam para uma concentração nos meses de dezembro, janeiro e fevereiro, sendo que os valores médios são superiores aos outros meses do período hidrológico.
\end{abstract} RClimdex.

Palavras chave: Climatologia. Climatologia Geográfica. Mudança climática. Climatologia estatística.

\section{Introdução}

Um dos mecanismos utilizados para a interpretação de dados climatológicos é a análise estatística que, por sua vez, permite avaliar um sistema climático a partir de inúmeras informações (variáveis climáticas) e, dessa forma, permite a observação de pressupostos quanto a mudanças num sistema climático (ZWIERS e VON STORCH, 2004, p. 674)

Em Climatologia, nota-se que o uso de ferramentas qualitativas e quantitativas se fazem necessárias para melhor compreender os diferentes regimes climáticos, bem com sua evolução temporal. Contudo, as variáveis (atributos) climáticas apresentam-se, por seus dados, como elementos heterogêneos e com flutuações. A pluviosidade pluviométrica consiste em um desses atributos que, reconhecidamente, tem 
grande dinamismo espacial (microclimática, mesoclimática e até nos climas globais) e temporalmente (Monteiro et al., 2015).

Santos et al. (2012), apontou para o aumento das chuvas consideradas intensas na região de Rio Claro/SP a partir do máximo acumulado em cinco dias consecutivos e no número de dias acima de $50 \mathrm{~mm}$ de chuva, uma vez que os autores reafirmam a presença de tendência positiva acerca de tais eventos se tornarem mais frequentes ao longo do tempo. Além disso, afirmam que existe correlação entre tais eventos interanuais com anomalias no Oceano Pacífico e Atlântico, sendo as regiões, nordeste e o sul do Brasil afetados negativa e positivamente respectivamente nessas influências.

Segundo Haylock et al. (2006, p. 1504) os índices de máximo de dias consecutivos secos e úmidos, bem como o máximo acumulado de chuvas em um único dia e em cinco dias, expressam, com significativa relevância, um indicativos de acompanhamento diário e unificado sobre as mudanças nos extremos de chuva, enquanto índices para a observação de padrões anômalos individuais no clima e sem a interferência de uma força de grande escala. Os autores afirmam ainda que, para interpretação de padrões de mudança na região sudeste da América do Sul, a observação de padrões de circulação e da média anual de pressão atmosférica nos oceanos se faz necessária.

\section{Metodologia}

O presente estudo se utilizou do tratamento quantitativo de dados chuvas diários de três estações climatológicas, sendo a primeira localizada na Universidade Federal de São Carlos (UFSCar) que é conveniada ao INMET, como sétimo distrito meteorológico desse e localizada na cidade de São Carlos/SP, a segunda estação climatológica, que está localizada na EMBRAPA/Pecuária Sudeste, também no município de São Carlos/SP e a terceira estação climatológica, que está localizada no CRHEA, no município de Itirapina/SP e pertence à EESC/USP (Escola de Engenharia de São Carlos/ Universidade de São Paulo). Essas se encontram, em média, $22 \mathrm{Km}$ distantes entre si a partir do rumo médio de $184^{\circ}$, sabendo que essas foram as estações climatológicas que se apresentaram na região de influência climática e, portanto, que apresentariam o mesmo comportamento climático por suas medições de temperatura e pluviosidade, além da escolha por 22 anos de dados, em função da existência de medições nos mesmos períodos entre as três estações analisadas, conforme expressa a figura 1. para trabalhos completos e 5 páginas para resumos expandidos, incluindo tabelas, figuras e referências bibliográficas. As seções deverão ser numeradas sequencialmente. 
XVII Simpósio Brasileiro de Geografia Fisica Aplicada

I Congresso Nacional de Geografia Física

\section{OS DESAFIOS DA GEOGRAFIA FÍSICA NA FRONTEIRA DO CONHECIMENTO \\ Instituto de Geociências - Unicamp \\ Campinas - SP \\ 28 de Junho à 02 de Julho de 2017}

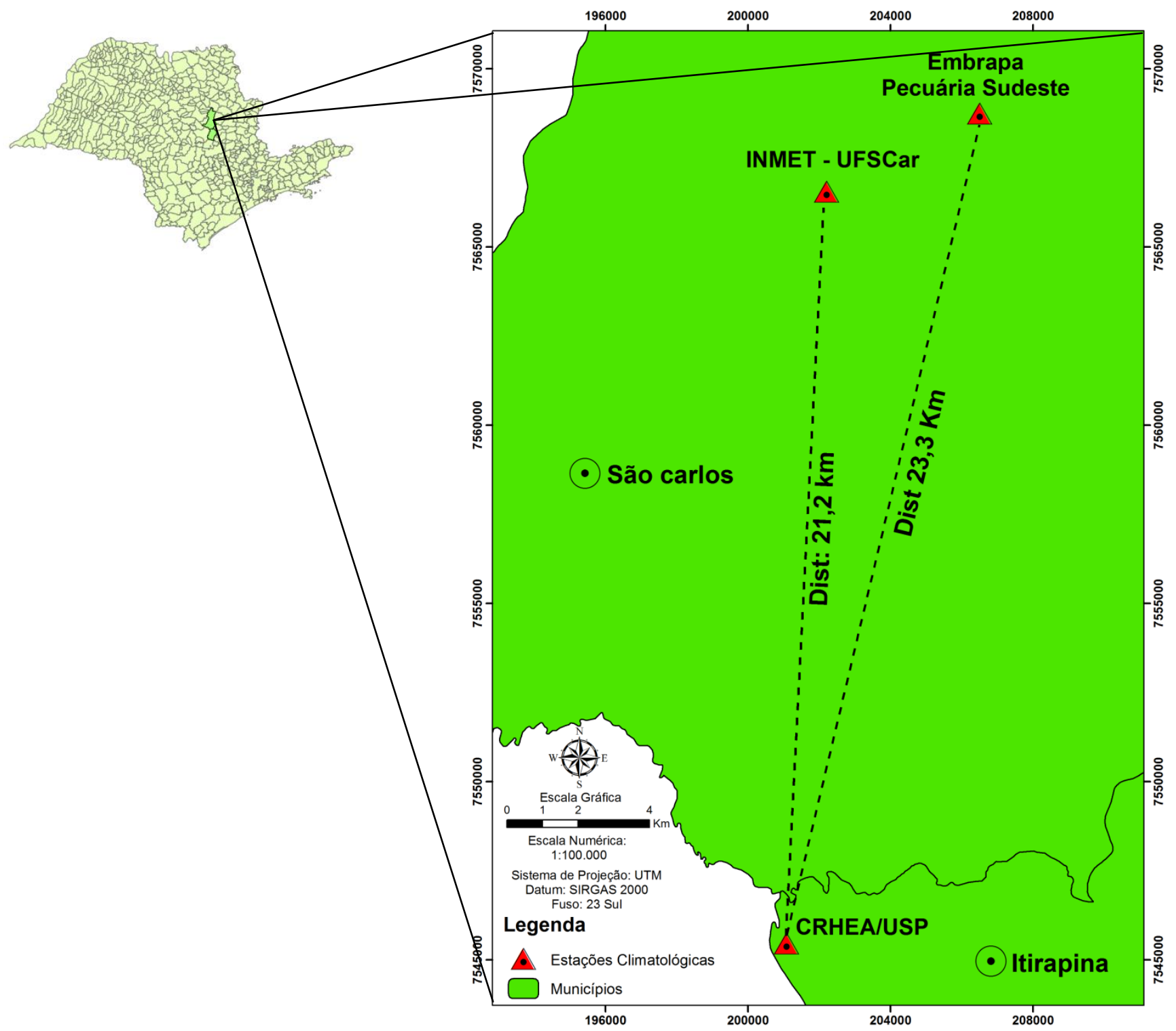

Figura 1 - Localização das estações climatológicas. Fonte. Adaptado de IBGE (2009)

Os dados pluviométricos diários e mensais das chuvas, em ambas as estações, foram selecionados para os meses de dezembro a março (período hidrológico), ou seja, o período que representa o maior volume pluviométrico anual.

Utilizou-se do software R e script RClimdex (ZHANG; YANG, 2004), por meio dos índices estabelecidos pelo ETCCDMI (Climate Change Detection Monitoring Indices) e utilizado em diversas pesquisas, como Haylock et. al. (2006), Rahimzadeh, Asgari e Fattahi (2008), Kioutsioukis, Melas e 
Zerefos (2010), Booth, Byrne e Jonhson (2011), Mekasha, Tesfaye e Duncan (2013), Sharma e Babel (2013) e Stephenson et. al. (2014) e, para o presente estudo, fora determinado o uso do índice para chuvas conforme a tabela 1 .

Tabela 1 - Índice climático interpretado pelo RClimdex.

\begin{tabular}{|c|c|c|c|}
\hline Índice (Identficação) & Nome do índice & Definição & Unidade observada \\
\hline RX 1 dia (RX1day) & $\begin{array}{l}\text { Máximo de chuva } \\
\text { acumulada em } 1 \text { dia }\end{array}$ & $\begin{array}{c}\text { Valor máximo de } \\
\text { chuva acumulada em } \\
\text { um único dia }\end{array}$ & $\mathrm{mm}$ \\
\hline $\begin{array}{l}\text { - } \quad \text { Admi } \\
\text { Send }\end{array}$ & $\begin{array}{l}\text { se } R R_{i j} \text { como a preci] } \\
\text { s valores máximos par }\end{array}$ & $\begin{array}{l}\text { tação diária acumulada } \\
\text { um dia no período } j \text { são } \\
j=\max \left(R R_{i j}\right)\end{array}$ & o dia $i$ no período $j$ \\
\hline
\end{tabular}

\section{Resultados e Discussão}

Os valores de máximos de chuva acumulada em único dia representam os dias mais chuvosos nas estações climatológicas ao longo da série histórica, sendo que, para tal possibilidade, pode-se notar que todos os valores máximos de chuvas nesse hipotético único dia ocorreram nos meses de janeiro, fevereiro, março, outubro, novembro ou dezembro.

As flutuações existentes nos dados dar-se-ão pelo caráter anual e mensal a partir do cálculo do índice e, para tanto, são apresentados os valores anuais e sua variabilidade mensal no semestre hidrológico. O gráfico 1 expressa o valor máximo de chuvas acumuladas em um único dia nas estações climatológicas entre 1993 e 2014, detalhando-os ano a ano. 


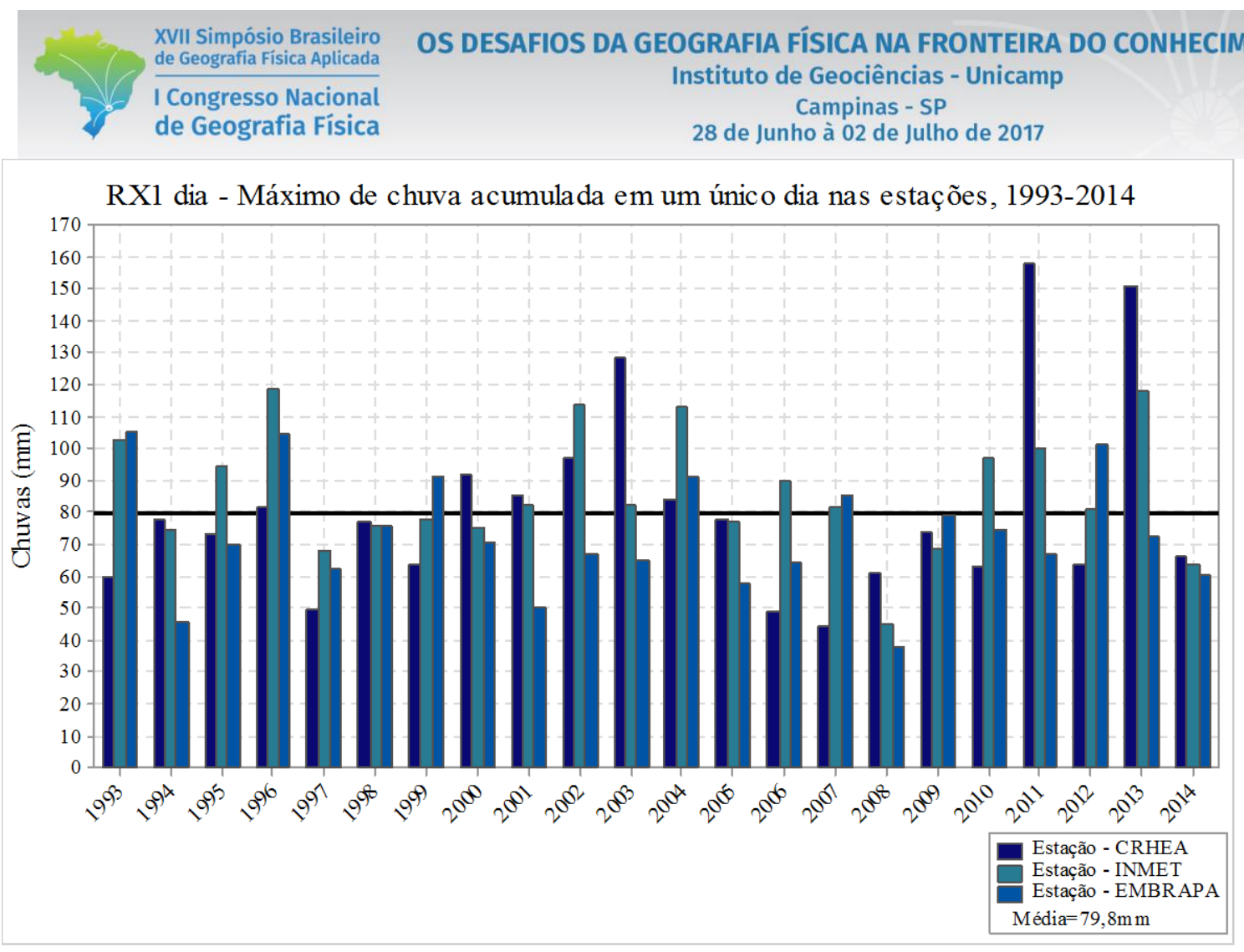

Figura 2 - RX 1 dia - Valor máximo de chuva acumulada em um único dia, nas estações, 1993-2014.

Para o RX de 1 dia, pode-se observar o valor médio de 79,8 $\mathrm{mm}$ de chuva entre as estações na série histórica, sendo os anos de 1997, 2008 e 2014 aqueles em que todas as estações climatológicas estiveram mais distantes do valor médio esperado do máximo de precipitação pluviométrica em um único dia e, em todos os anos obteve-se ao menos $45 \mathrm{~mm}$ de chuva num único dia, sendo que esses apresentam-se sempre no período do semestre hidrológico, o que totaliza $81 \%$ dos anos, em média, próximos ao valor médio esperado. Além disso, a estação climatológica do CRHEA/USP foi a que apresentaram os maiores valores extremos diários de chuva, que foram nos anos de 2003, 2011 e 2013, com 128, 158 e 151 mm de chuvas respectivamente.

Os dados de valor máximo acumulado em um único dia favorecem para a compreensão das chuvas extremas, sendo que, no máximo valor acumulado em um único dia de chuva, pode-se estabelecer parâmetros base para os anos, sendo que, a média do valor máximo acumulado em um único dia para as estações estudadas foi de, aproximadamente $80 \mathrm{~mm}$ e, o mínimo desses valores máximos de um único dia esteve em, aproximadamente, $45 \mathrm{~mm}$, ou seja, espera-se que existam dias chuvosos em todos os anos em que as chuvas totalizem $45 \mathrm{~mm}$ num único dia, ou seja, que irão ocorrer dias considerados muito úmidos e que podem trazer impactos significantes no espaço rural e urbano, mesmo que exista uma grande dificuldade na observação de, em que determinado mês de um ano esse dia ocorrerá. Contudo, pode-se 


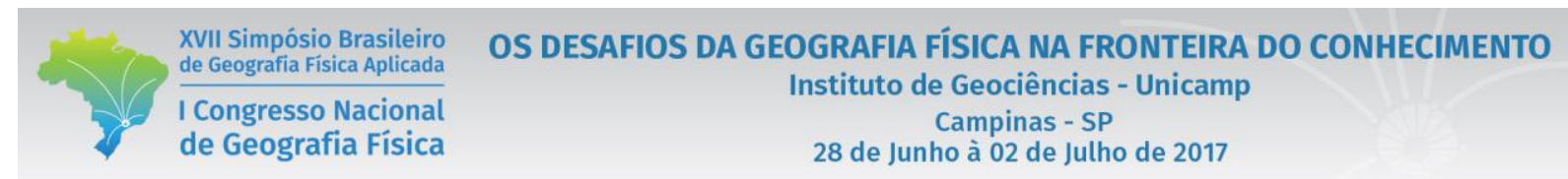

notar que as chuvas consideradas como valores máximos acumulados em um dia (RX 1 dia) sempre ocorreram dentro do período do semestre hidrológico, o que direciona para um período do ano (sazonal) em que as chuvas irão se concentrar, sendo que, nos meses de dezembro, janeiro e fevereiro os valores médio são superiores aos dos outros meses do semestre hidrológico (Figura 3).

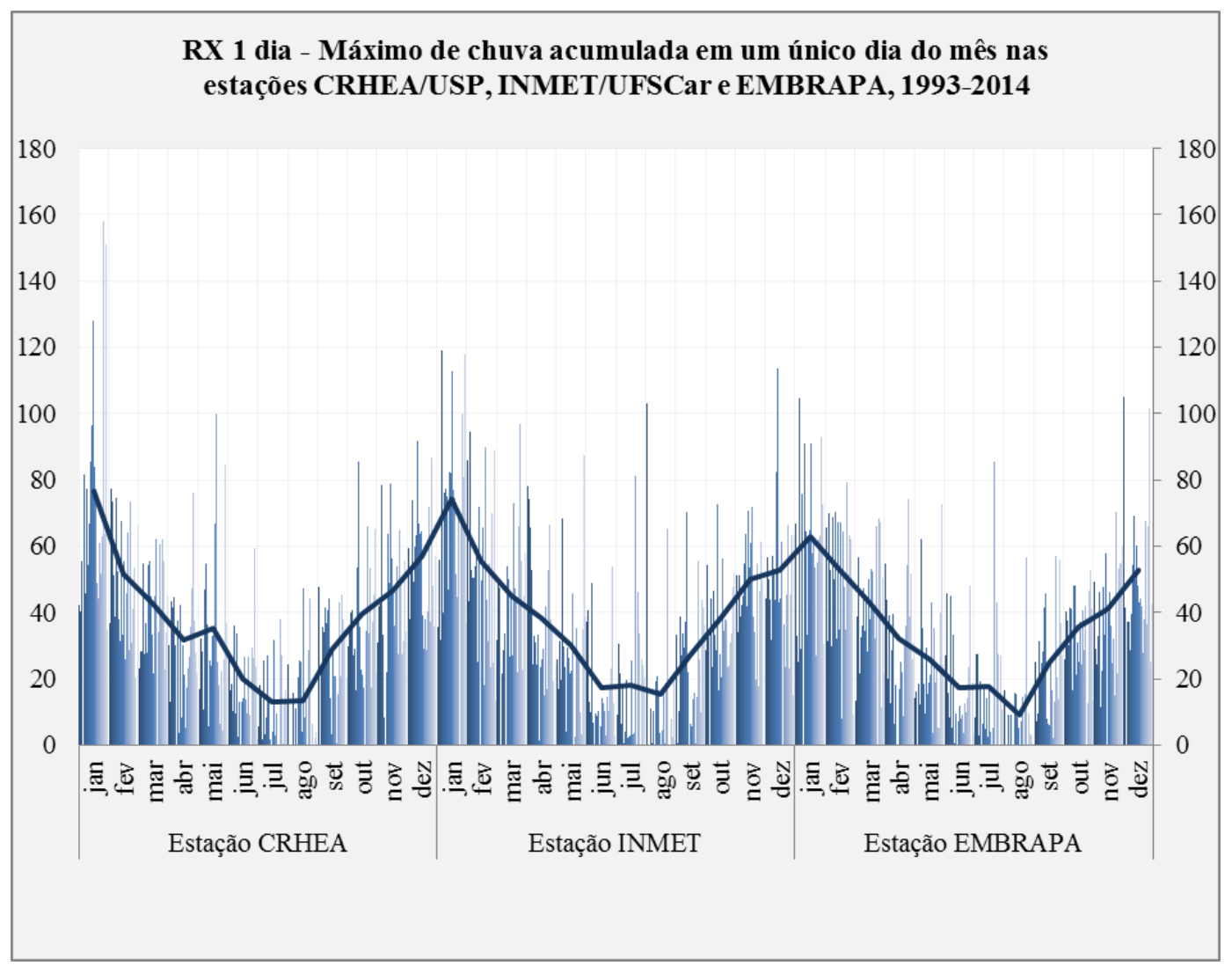

Figura 3 - RX 1 dia - Distribuição do valor máximo de chuva acumulada em um único dia, mensalmente, 1993-

2014.

O mês de dezembro apresentou-se como um dos mais chuvosos no período de um ano (janeiro a dezembro), sendo que esse, juntamente com o mês de janeiro, é os meses de maiores valores de chuva para o período e na série histórica. O gráfico 6 representa o máximo acumulado em um único dia chuvoso no mês de dezembro na série histórica adotada.

Pode-se observar que o último ano da série histórica, 2014, encontra-se acima da média para as estações do CRHEA/USP e INMET/UFSCar, sendo que a estação pertencente a EMBRAPA apresentou-se abaixo da média esperada para o mês no ano de 2014, representando as flutuações existentes entre as estações por seus valores no índice (Figura 4). 


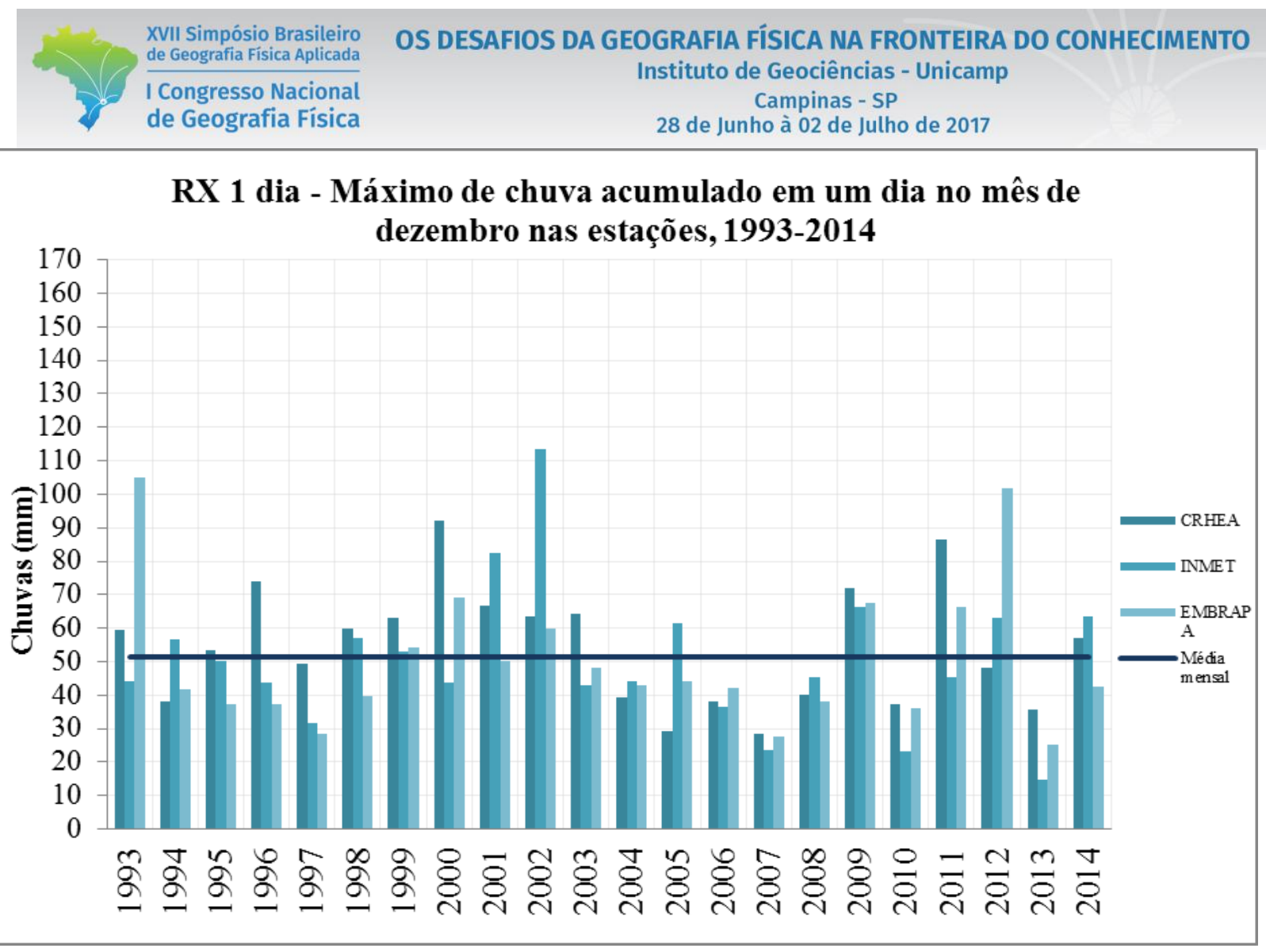

Figura 4 - RX 1 dia - Valor máximo de chuva acumulada em um único dia no mês de dezembro nas estações, 19932014.

O mês de dezembro apresentou-se como o segundo de maior média de precipitação acumulada em um único dia. Já no mês de janeiro, nota-se o maior valor médio de chuvas acumuladas em um único dia, para a série histórica adotada e em todas as estações climatológicas, como expressa a figura 5. 


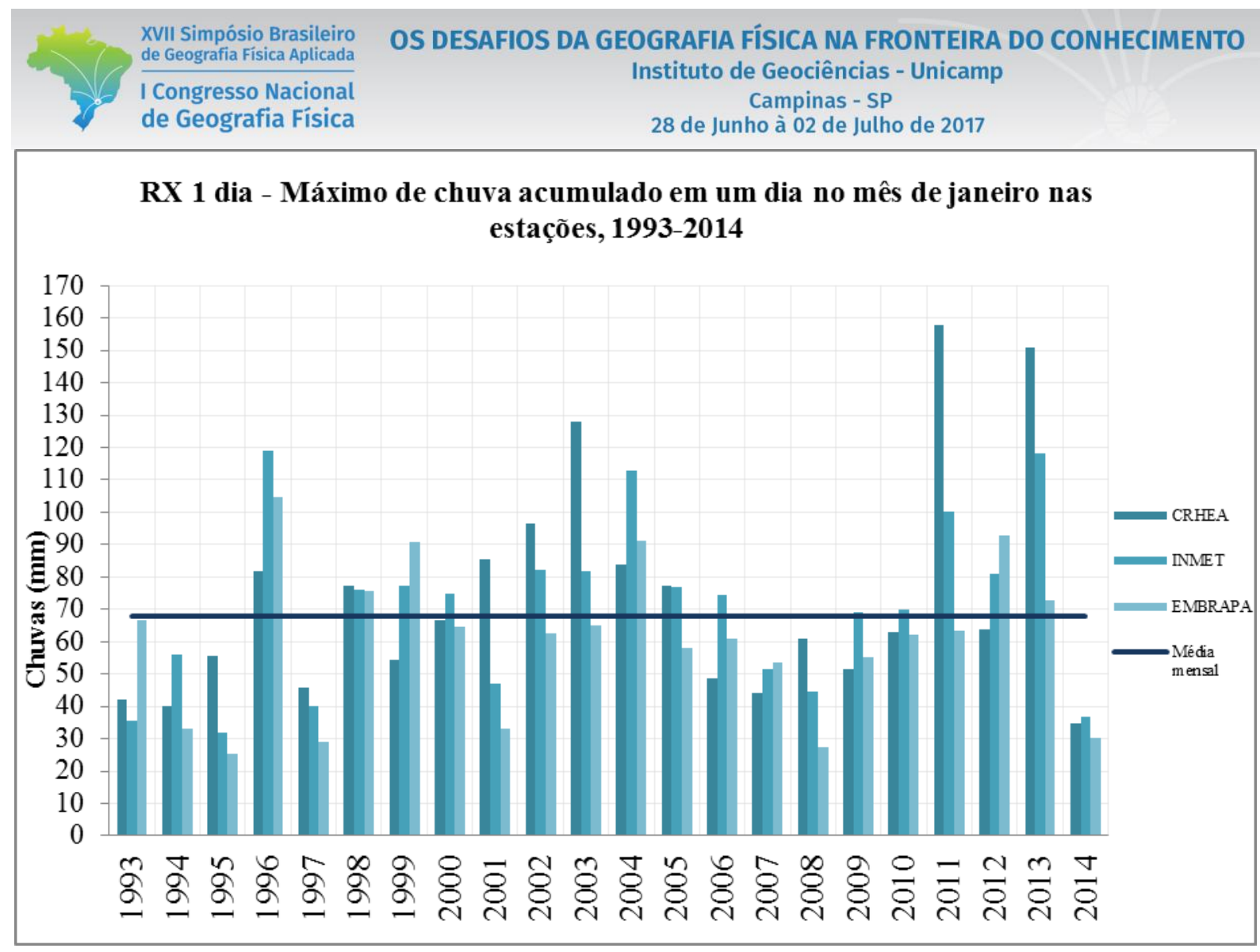

Figura 5 - RX 1 dia - Valor máximo de chuva acumulada em um único dia no mês de janeiro nas estações, 19932014.

No mês de janeiro encontram-se os maiores valores máximos de chuva acumulada em um único dia na série histórica adotada no presente estudo, sendo que quase $60 \%$ dos anos estiveram acima da média esperada para o período. Além disso, o ano de 2014 se apresentou abaixo do valor esperado para o mês de janeiro, o que é recorrente em vários outros anos na série histórica.

Para esse mesmo mês notou-se os maiores valores de chuva acumulada em único dia, sendo $158 \mathrm{~mm}$ e 151 mm nos anos de 2011 e 2013 respectivamente na estação localizada no CRHEA, valores esses que são os mais elevados em todas as estações analisadas em todos os meses de maiores valores de chuva em um dia chuvoso.

Com isso, o mês de janeiro, mesmo com grandes flutuações interanuais nos dados de chuvas, apresentou índices pluviométricos significativos na série histórica.

Para o mês de fevereiro também se notou uma grande diferença entre os dados das estações, uma vez que os últimos cinco anos os valores de chuvas nessas estações, mesmo agrupadas em um mesmo cenário climático por sua gênese, apresentaram comportamentos pluviométricos distintos quanto ao máximo de 


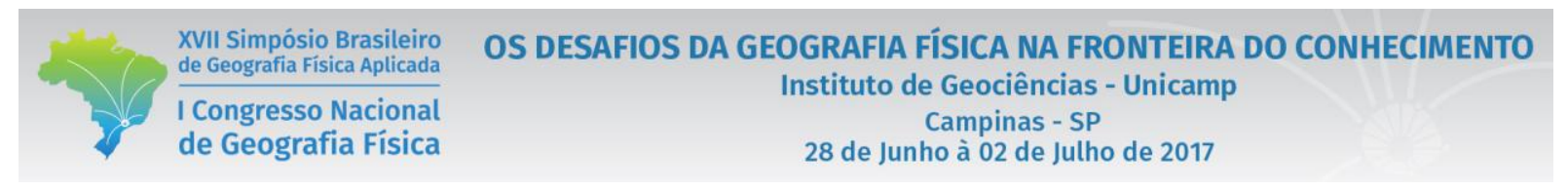

chuva acumulada em um único dia, onde a estação localizada no CRHEA registrou índices superiores às outras estações.

Tais aspectos são observados a partir da figura 6, que expressa o valor máximo de chuva acumulada em um único dia nas estações climatológicas.

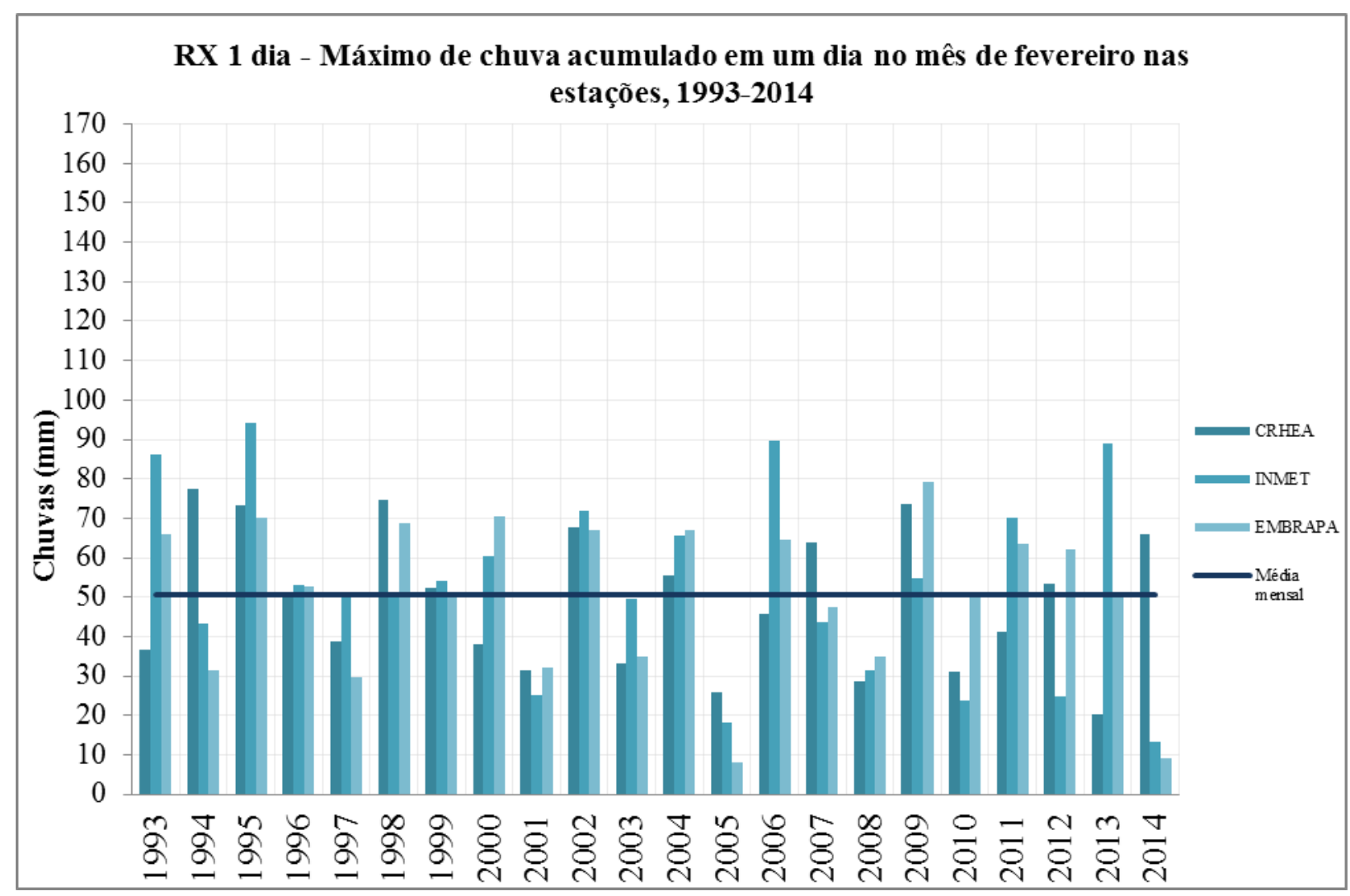

Figura 6 - RX 1 dia - Valor máximo de chuva acumulada em um único dia no mês de fevereiro nas estações, 19932014.

O período hidrológico e sua representação a partir do RX de 1 dia representam o acúmulo de precipitação pluviométrica em um único dia, sendo que as flutuações observadas junto aos dados são significativas a apontam para a concentração dos dias mais chuvosos entres os meses de dezembro e janeiro, sendo que os meses de setembro e fevereiro são aqueles de mais apresentaram flutuações nos dados de chuvas acumuladas e, nos meses de outubro e março é possível observar o aumento e a diminuição das médias acumuladas em um único dia respectivamente na série histórica. 
A análise dos dados também permite se observar diferenças entre o comportamento pluviométrico entre as estações do CRHEA/USP, do INMET/UFSCar e da EMBRAPA, sendo que, mesmo essas configurando uma mesma gênese climática têm registros cronológicos e quantitativos que variam entre si.

Com isso, os diferentes índices mostram grande dinamismo na interpretação dos dados de chuvas para a região de São Carlos/SP, o que permite identificar períodos recorrentes de chuvas extremas, agora estabelecidas a partir dos dados obtidos da própria região e, portanto, sem suposições acerca de sua ocorrência e alicerçadas pela identificação in situ de seu comportamento registrado em estações climatológicas.

Por fim, a discussão existente quanto às mudanças nos regimes climáticas existentes na região sudeste do Brasil, região essa onde foi realizado o trabalho, apresentadas pelo IPCC (2014), não apresentam suporte suficientes de trabalhos e dados que comprovem a sua existência, além de não admitir o caráter dinâmico e de flutuação nos climas regionais e locais, elementos que ocorrem nessas áreas e devem agrupar um maior volume de dados e trabalhos para que não existam afirmações infundadas quanto às alterações no comportamento das temperaturas e das chuvas e que se admite serem os elementos atmosféricos que compreendem tais mudanças nos regimes dos climas.

\section{Considerações Finais}

As diferenças entre as estações climatológicas na escala espacial, apesar de não serem muito distantes espacialmente, apresentaram significativas diferenças entre os dados, sendo que as estações localizadas em São Carlos/SP (INMET/UFSCar e EMBRAPA) apresentavam inúmeras vezes dados congruentes entre si, enquanto a estação climatológica do CRHEA/USP apresentou um comportamento de semelhança em apenas alguns índices.

Inúmeros trabalhos apontam para a existência de tendências positivas ou negativas para alterações climáticas, porém, apenas com pressupostos e modelos estatísticos que não incorporam os inúmeros aspectos que contribuem para a ocorrência de chuvas, por exemplo. Essa tipologia de trabalhos são comumente utilizados e referenciados como os de maior relevância no eixo temático de climatologia, mesmo que existam pesquisas que contrapõem essa observação linear dos climas e, para tanto, seria de grande esforço por parte de próximos trabalhos, que se não houvesse uma visão unilateral quanto ao entendimento do clima por sua gênese e alterações temporais, mas que o entendimento do clima se dê a 
partir de elementos qualitativos e quantitativos, ou seja, para que se utilizem ferramentas de uma abordagem clássica do clima e de seu caráter dinâmico, a fim de melhor compreender o comportamento dos diferentes tipos de clima.

Dentre as principais potencialidades de uma análise quantitativa para dados climatológicos, destaca-se a possibilidade de uma interação gráfica junto aos dados por sua realidade temporal, o que permitiu a confecção de inúmeros gráficos representativos quanto ao comportamento das chuvas na região, além disso, o uso de uma ferramenta estatística computacional pautada na análise climatológica favorece a análise voltada aos climas. Com isso, o uso de dados diários em pesquisas de climatologia por esse uso quantitativo pode facilitar o entendimento da dinâmica atmosférica que não foi observado, apenas, valores médios mensais ou anuais e que ocultam tal dinamismo.

Além disso, a presença de flutuações nas séries de dados e, a partir de uma abordagem dinâmica quanto à distribuição das chuvas, a determinação de tendências poderia influir no julgamento inadequado quanto ao curso das chuvas para os próximos anos. Dessa forma, o estudo prezou pela descrição do comportamento das chuvas na região de São Carlos/SP e não pela análise de tendências na série histórica.

Contudo, a determinação de valores que podem ser considerados efêmeros nas chuvas diárias, contribuiu para a melhor visibilidade da quantidade de chuvas e, dessa maneira, tornando possível a identificação de chuvas extremas com o caráter regional e a partir de dados obtidos.

O apontamento dos diferentes usos do presente estudos são inúmeros, contudo, ressaltam a necessidade de contextualizar sua aplicabilidade, ora para o planejamento agrícola junto à produção de diferentes culturas da agricultura, períodos para o plantio, ou então, para órgãos de planejamento e ordenamento territorial urbano que, a partir desses, podem estabelecer políticas pautadas no entendimento climático, por meio das chuvas, em situações desastrosas, como enchentes ou até a disponibilidade de água para captação e distribuição nos municípios da região, reafirmando o paradigma climatológico como necessário sob a ótica do planejamento em diferentes âmbitos da ciência e na tomada de decisão.

Como sugestão para trabalhos futuros, o melhor entendimento da dinâmica dos climas na região tropical e a adequação das ferramentas teórico-metodológicas poderiam contribuir para o melhor entendimento do comportamento climático local e regional. Além disso, a insistência em uma abordagem escalar global, atendendo apenas a uma característica estatística e que não respeite as especificidades de cada região climática pode dificultar a observação de variações, oscilações, mudanças, etc., que existem nos climas tropicais para que não haja apenas uma abordagem puramente estocástica ou então de uma afirmação de natureza linear. 
Além disso, destaca-se a importância de averiguar as repercussões das flutuações quantitativas das chuvas no espaço geográfico regional, a fim de melhor representar os diferentes impactos espaciais e temporais de tais eventos climáticos.

\section{Agradecimentos}

Ao CNPQ e a CAPES pelo fomento ao desenvolvimento da pesquisa. À Embrapa Pecuária Sudeste. À Universidade Federal de São Carlos. À Escola de Engenharia de São Carlos (CRHEA/EESC/USP).

\section{Bibliografia}

BOOTH, E. L. J.; BYRNE, J. M.; JOHNSON, D. L. Climatic changes in western North America, 1950-2005. International Journal of Climatology, 32(15), 2283-2300, 2012.

HAYLOCK, M. R. et al. Trends in Total and Extreme South American Rainfall in 1960-2000 and Links with Sea Surface Temperature. Journal of Climate. Vol. 19. 1490-1512, 2006.

KIOUTSIOUKIS, I.; MELAS, D.; \& ZEREFOS, C. Statistical assessment of changes in climate extremes over Greece (1955-2002). International Journal of Climatology, 30(11), 1723-1737, 2010.

MEKASHA, A.; TESFAYE, K.; DUNCAN, A. Trends in daily observed temperature and precipitation extremes over three Ethiopian eco-environments. International Journal of Climatology, 34(6), 1990-1999, 2013.

MONTEIRO, C. A. F.; MENDONÇA, F. A;, ZAVATTINI, J. A.; NETO, J. L. S.. A Construção da Climatologia Geográfica no Brasil. Campinas: Alínea, 2015.

RAHIMZADEH, F.; ASGARI, A.; FATTAHI, E. Variability of extreme temperature and precipitation in Iran during recent decades. International Journal of Climatology, 343(August 2008), 329-343. 2009.

SANTOS, C. A.; SATYAMURTY, P.; GOMES, O. M.; DA SILVA, L. E. M. G. Variability Of Extreme Climate Indices At Rio Claro, São Paulo, Brazil. Revista Brasileira de Meteorologia. v.27, n.4, 395 - 400, 2012.

SHARMA, D.; BABEL, M. S. Trends in extreme rainfall and temperature indices in the western Thailand. International Journal of Climatology, 2013. 


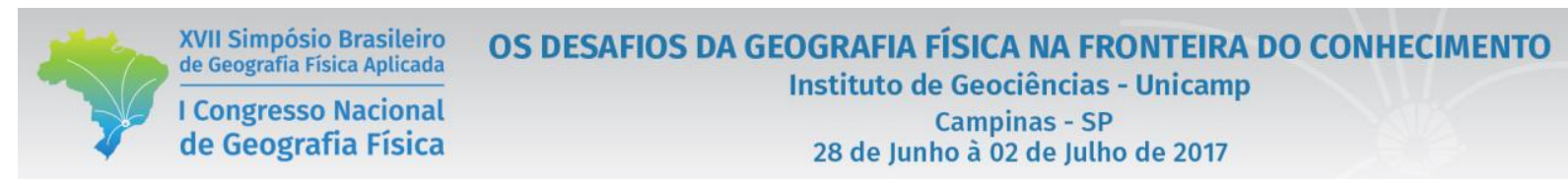

STEPHENSON, T. S.; VINCENT, L. A.; ALLEN, T.; VAN MEERBEECK, C. J.; MCLEAN, N.; PETERSON, T. C.; ... TROTMAN, A. R. Changes in extreme temperature and precipitation in the Caribbean region, 19612010. International Journal of Climatology, 2014.

ZHANG, X.; YANG, F. RClimDex (1.0) User Guide. Climate Research Branch Environment Canada: Downsview, Ontario, Canada, 2004.

ZWIERS, F. W.; VON STORCH, H. On the role of statistics in climate research. International Journal of Climatology, 24(6), 665-680, 2004. 